\title{
Prevalence of Associated Endocrine Diseases in Patients with Neurofibromatosis Type 1
}

\author{
Aysha Alshahrani ${ }^{1}$ Zainah Abuoliat ${ }^{2}$ Awad Saad Alshahrani ${ }^{3,4}$ Mohammed Ali Al Balwi ${ }^{4,5}$ \\ 1 Family Medicine Department, King Fahad Medical City, Riyadh, Saudi \\ Arabia \\ 2 Dermatology Department, King Salman bin AbdulAziz Hospital, \\ Riyadh, Saudi Arabia \\ ${ }^{3}$ Division of Adult Endocrinology, Department of Medicine, King \\ Abdulaziz Medical City, Riyadh, Saudi Arabia \\ ${ }^{4}$ College of Medicine, King Saud bin Abdulaziz University for Health \\ Sciences, King Abdullah International Medical Research Center, \\ Riyadh, Saudi Arabia \\ ${ }^{5}$ Division of Molecular pathology section, Department of Pathology, \\ King Abdulaziz Medical City, Riyadh, Saudi Arabia \\ Address for correspondence Mohammed Ali AlBalwi, MD, \\ Department of Pathology and Laboratory Medicine, King Abdulaziz \\ Medical City, Ministry of National Guard - Health Affairs, P.O. Box \\ 22490, Riyadh 11426, Kingdom of Saudi Arabia \\ (e-mail: balwim@ngha.med.sa). \\ Avicenna J Med 2022;12:16-20.
}

\begin{abstract}
Keywords

- neurofibromatosis type 1

- endocrine diseases

- NF-1

Background Neurofibromatosis type 1 (NF-1) is an autosomal dominant neurocutaneous disorder that increases the risk of developing benign and malignant tumors. Several associated endocrine diseases in NF-1 patients have been explained in the literature. Thus, this study aims to assess the endocrine manifestations as there no previous local data have discussed this association.

Methods A retrospective cross-sectional study was conducted at KAMC and KASCH, Riyadh, Saudi Arabia by including all patients genetically confirmed with NF1 from 2004 until 2019 using a consecutive non-probability sampling technique. The included data were demographics, consanguinity, genetic variant mutations as well as associated endocrine diseases.

Results The prevalence of patients with associated endocrine diseases was estimated to be $19.4 \%$. Short stature showed the highest frequency of associated endocrine diseases followed by subclinical hypothyroidism. Positive consanguinity, sporadic mutation, and pathogenic variant showed high frequencies.

Conclusion The coexistence of endocrine diseases was found in NF-1 patients. Therefore, screening for endocrine abnormality in patients with NF-1 by comprehensive history and physical exam as well as investigations to minimize complications and the late presentation should be considered; however, further studies are necessary to address the need.
\end{abstract}

published online

February 18, 2022
DOI https://doi.org/ 10.1055/s-0041-1742197. ISSN 2231-0770.

\footnotetext{
C 2022. Syrian American Medical Society. All rights reserved. This is an open access article published by Thieme under the terms of the Creative Commons Attribution-NonDerivative-NonCommercial-License, permitting copying and reproduction so long as the original work is given appropriate credit. Contents may not be used for commercial purposes, or adapted, remixed, transformed or built upon. (https://creativecommons.org/ licenses/by-nc-nd/4.0/)

Thieme Medical and Scientific Publishers Pvt. Ltd., A-12, 2nd Floor, Sector 2, Noida-201301 UP, India
} 


\section{Introduction}

Neurofibromatosis type 1 (NF-1), was first described by Von Recklinghausen in $1882,{ }^{1-3}$ is a common neurocutaneous disorder that increases the risk of developing benign and malignant tumors in patients with NF-1. ${ }^{1}$ It is considered to be an autosomal dominant caused by a mutation in the NF1 gene located in 17q11.2 with half of the cases are familial and the other half are sporadic mutations. ${ }^{4}$ The prevalence of NF1 has been estimated to be $\sim 1 / 3500$ in the USA and the United Kingdom. ${ }^{5}$ The clinical manifestations include cafe au lait spots; cutaneous, subcutaneous, and plexiform neurofibromas; axillary and/or inguinal freckling; Lisch nodules; intracranial gliomas; malignant peripheral nerve sheath tumors; vascular and bone dysplasia. ${ }^{6}$ Endocrine diseases and neoplasia also occur in patients with NF-1, which may include phaeochromocytomas/paragangliomas (PPGLs), primary hyperparathyroidism (PHPT), gastroenteropancreatic neuroendocrine tumors, thyroid, and other adrenal tumors. ${ }^{2}$

Growth hormone deficiency and short stature are common in children with NF-1, but with unknown incidence. ${ }^{3}$ Central precocious puberty represents the most common endocrine disorder associated with NF-1 during childhood with a prevalence of $3 \%$, compared with $0.6 \%$ in the general population. ${ }^{7}$ Primary hyperparathyroidism (PHPT) has been rarely reported as isolated cases and the majority is due to the presence of solitary parathyroid adenoma. ${ }^{8}$ The prevalence of phaeochromocytomas/paragangliomas (PHAEO/PG) in patients with NF-1 is $\sim 1$ to $5.7 \%^{8}$

The purpose of this study was to identify the endocrine manifestations in patients with NF-1 as there are no previous local data that have discussed this association in the literature. In addition, this study will help to consider implementing a screening evaluation of endocrine dysfunction in NF-1 patients, thus minimizing complications and late presentations.

\section{Materials and Methods}

This study was a retrospective cross-sectional study conducted at King Abdulaziz Medical City (KAMC) and King Abdullah Specialized Children's hospital, Riyadh, Saudi Arabia, by including all patients diagnosed with NF1 from 2004 until 2019 to identify associated endocrine diseases. The study was approved by the ethical Institutional Review Board (IRB) committee at King Abdullah International Medical Research Center (KAIMRC) under a protocol (RC19/306/R). Data were retrospectively collected by reviewing the electronic medical records from the BestCare system and the Molecular Pathology and Genetics database. It included patients' demographic data that were generated from patient history and physical examination records. Data included age, gender, consanguinity, mode of mutations, genetics variants as well as associated endocrine diseases. All patients' genomic DNA samples were tested for the full NF1 gene using bidirectional Sanger sequencing and mutations were identified using CLC Genomics Workbench v8.0 (CLC bio, Aarhus, Denmark), and the mutations were checked against the updated public database (dSNPs; http://www.ncbi.nih.gov) and the Catalogue of Somatic Mutation in Cancer (COSMIC, https://cancer.sanger.ac.uk). Mutations pathogenicity (disease-causing) were detected using various bioinformatics methods, such as "Mutation Taster" (http://www.mutationtaster.org). A consecutive non-probability sampling technique was used. Data entry was performed using the Excel program and was statistically analyzed using the Statistical Package for the Social Sciences [SPSS], Version 20.0 (IBM Corporation, Armonk, NY, USA). Descriptive statistics were presented as frequency and percentage for categorical variables (gender, presence of consanguinity, mode of mutations, genetics variants classifications). Mean \pm standard deviation will be used for numerical variables (age). This study was approved by the Institutional Review Board in KAIMRC.

\section{Results}

The study included 62 patients (-Tables 1 and 2) who were genetically confirmed with NF1. There were 32 (51.61\%) male patients and 30 (48.39\%) female patients. Generally, the mean age in years was $16.36 \pm 14.46$, and the interquartile range (IQR) was 12 with the majority of cases (69.35\%) below the mean age. In males, the mean age in years was $15.73 \pm 12.91$, with an IQR of 11.75 , whereas the mean age in years and IQR were $16.94 \pm 15.66$ and 13.25 in females, respectively. Among NF-1 cases, 12 cases had endocrine associated disorders. Positive consanguinity was found in 31 cases (50\%), and sporadic mutation was found in 28 cases (45.16\%), whereas familial mutation was found in 30 cases (48.39\%). The pathogenic variant of gene classification carried the highest rate with $66.13 \%$. The prevalence of patients with associated endocrine diseases ( - Table 1 ) was estimated to be $19.4 \%$. Short stature showed the highest frequency of associated endocrine diseases in five cases (8.06\%), followed by subclinical hypothyroidism, which was presented in four cases $(6.45 \%)$, and one case $(1.61 \%)$ for each of the following endocrine associated disorders namely thyroid nodule, precocious puberty, and MEN-II.

The mean age of patients with the associated endocrine disease was $20.28 \pm 20.67$ years ( - Table 1 ). Among those patients, males outnumbered females with a ratio of $4: 1$. Positive consanguinity (58.30\%) outnumbered negative consanguinity (41.70\%), and sporadic mutation (58.30\%) outnumbered familial mutation $(41.70 \%)$ as well. Among the seven cases who had a history of consanguinity, five cases (41.70\%) had their mode of mutation sporadic compared with two cases (16.67\%) who had a familial mode of mutation. The pathogenic variant of gene classification carried the highest rate among cases with endocrine disorders with $66.67 \%$.

\section{Discussion}

The concomitant occurrence of endocrine diseases in patients with NF-1 has been explained in many previous studies. ${ }^{1-3,7}$ However, there is an unknown prevalence in the 
Table 1 Demographical data of NF-1 patients $(n=62)$

\begin{tabular}{|c|c|c|c|}
\hline \multicolumn{2}{|l|}{ Characteristic } & Frequency & Percentage \\
\hline \multicolumn{2}{|l|}{ Mean of age (y) } & \multicolumn{2}{|c|}{$16.36 \pm 14.46$} \\
\hline \multirow[t]{2}{*}{ Gender } & Male & 32 & 51.61 \\
\hline & Female & 30 & 48.39 \\
\hline \multirow[t]{2}{*}{ Consanguinity } & Positive & 31 & 50 \\
\hline & Negative & 31 & 50 \\
\hline \multirow{3}{*}{$\begin{array}{l}\text { Mode of } \\
\text { mutation }\end{array}$} & Sporadic & 28 & 45.16 \\
\hline & Familial & 30 & 48.39 \\
\hline & Unknown & 4 & 6.45 \\
\hline \multirow{2}{*}{$\begin{array}{l}\text { Presence of } \\
\text { consanguinity }\end{array}$} & Sporadic & 18 & 29.03 \\
\hline & Familial & 13 & 20.97 \\
\hline \multirow{2}{*}{$\begin{array}{l}\text { Absence of } \\
\text { consanguinity }\end{array}$} & Sporadic & 10 & 16.13 \\
\hline & Familial & 17 & 27.42 \\
\hline \multirow[t]{3}{*}{ NF 1 mutation } & $\begin{array}{l}\text { Pathogenic } \\
\text { Variant }\end{array}$ & 41 & 66.13 \\
\hline & $\begin{array}{l}\text { Likely } \\
\text { pathogenic }\end{array}$ & 13 & 20.97 \\
\hline & $\begin{array}{l}\text { Variants of } \\
\text { uncertain } \\
\text { significance }\end{array}$ & 8 & 12.90 \\
\hline \multicolumn{2}{|c|}{ Endocrine disorder } & 12 & 19.35 \\
\hline \multicolumn{2}{|l|}{ Short stature } & 5 & 8.06 \\
\hline \multicolumn{2}{|c|}{ Subclinical hypothyroidism } & 4 & 6.45 \\
\hline \multicolumn{2}{|l|}{ Thyroid nodules } & 1 & 1.61 \\
\hline \multicolumn{2}{|c|}{ Precocious puberty } & 1 & 1.61 \\
\hline \multicolumn{2}{|c|}{$\begin{array}{l}\text { Variant of MEN II: Concurrent } \\
\text { of bilateral } \\
\text { pheochromocytoma, primary } \\
\text { hyperparathyroidism due to } \\
\text { parathyroid adenoma, and } \\
\text { multinodular goiter }\end{array}$} & 1 & 1.61 \\
\hline
\end{tabular}

literature that describes this association. This study aims to identify the prevalence of associated endocrine diseases in all ages and both genders with genetically confirmed NF-1 patients, which was found to be $19.4 \%$ with a mean age of $20.28 \pm 20.67$ years. This high stander deviation describes late presentations of some NF-1 patients with associated endocrine abnormalities. Endocrine diseases that have been discovered in our study were short stature, followed by subclinical hypothyroidism, thyroid nodules, precocious puberty, and one case of concurrent multinodular goiter, bilateral pheochromocytoma, and primary hyperparathyroidism due to parathyroid adenoma. Short stature was found in five patients (8.06\%) who were all males with a mean age of $13.4 \pm 3.1$ years. Positive consanguinity was found in two patients of those patients with short stature; one had familial and the other had a sporadic mutation. However, one out of the remaining three patients who had a negative history of consanguinity was found to have a sporadic mutation. Patients in this study with short stature
Table 2 Characteristics of patients with associated endocrine diseases $(n=12)$

\begin{tabular}{|l|l|l|l|}
\hline \multicolumn{2}{|l|}{ Characteristic } & Frequency & Percentage \\
\hline \multicolumn{3}{|l|}{ Mean of age (y) } & \multicolumn{2}{|l|}{$20.28 \pm 20.67$} \\
\hline Gender: male to female ratio & $4: 1$ & $75: 25$ \\
\hline \multirow{2}{*}{ Consanguinity } & Positive & 7 & 58.30 \\
\cline { 2 - 4 } & Negative & 5 & 41.70 \\
\hline Mode of mutation & Sporadic & 7 & 58.30 \\
\cline { 2 - 4 } & Familial & 5 & 41.70 \\
\hline Sporadic and consanguineous & 5 & 41.70 \\
\hline Familial and consanguineous & 2 & 16.67 \\
\hline NF-1 mutation & $\begin{array}{l}\text { Pathogenic } \\
\text { variant }\end{array}$ & 8 & 66.67 \\
\cline { 2 - 4 } & $\begin{array}{l}\text { Likely } \\
\text { pathogenic }\end{array}$ & 2 & 16.67 \\
\cline { 2 - 4 } & $\begin{array}{l}\text { Variants of } \\
\text { uncertain } \\
\text { significance }\end{array}$ & 2 & 16.67 \\
\hline
\end{tabular}

mainly carried the pathogenic variants. In previous studies, children with NF-1 tend to be shorter than unaffected individuals with two standard deviations or more below the reference population mean in $13 \%$ and below the third percentile in $15 \% .{ }^{9}$ Subclinical hypothyroidism was discovered in four cases $(6.45 \%)$, three of which were males and one female in this study with a mean age of $9.1 \pm 5.8$ years. Positive consanguinity was found in three patients who also showed sporadic NF-1 mutations. Moreover, one patient was found to have negative consanguinity history with a familial mutation. Pathogenic and variant of uncertain significance was equally found in two patients of affected individuals with subclinical hypothyroidism. Previous reports have addressed the association of NF-1 with autoimmune thyroiditis, thyroid nodules, and neuroendocrine tumors. ${ }^{10-13}$ The prevalence of subclinical hypothyroidism in children was estimated to be less than $2 \% .{ }^{14}$ In Serhat Güler study, a case of a 10-year-old girl with coexisting NF-1 and subclinical hypothyroidism was reported. ${ }^{10}$ They reported a $1.2 \%$ prevalence of subclinical hypothyroidism. ${ }^{10}$ However, we have found four cases of subclinical hypothyroidism that corresponded to $6.45 \%$ of our cases. It is yet unclear whether the association of NF-1 with subclinical hypothyroidism is certain or coincidental. Nevertheless, the rarity of both conditions and the relatively higher prevalence of subclinical hypothyroidism in such a Saudi cohort would warrant further research and investigations. Bilateral benign follicular thyroid nodules, one nodule in each lobe, were discovered in a 52-year-old woman who had a sporadic NF-1 mutation and carried the pathogenic variant. In a previous Saudi study, the incidence of thyroid nodules and malignancies increased with age reaching its peak within the fifth decade. ${ }^{15} \mathrm{Al}-$ though this might fall against the certainty of associated thyroid nodules in NF1, there is a higher probability of nodules and malignancies to occur among NF1 patients. ${ }^{7,15}$ 
Thyroid morphology and function studied in 17 patients with NF-1 showed nodular goiter in 10 patients, and after those 10 patients have undergone thyroidectomy, thyroid cancer was found in 2 cases (11.76\%), indicating that thyroid disease may be underestimated in the context of NF-1.,11 Although thyroid cancer is rarely reported in the literature, it might be detected incidentally in patients by ultrasonography especially when it is a small nodule, as the case reported by Bu Kyung Kim, which promotes the need for screening in NF-1 patients. ${ }^{16,17}$

Precocious puberty was noticed in a 15-year-old boy who also had optic chiasm glioma and was diagnosed at the age of 6 years old. He had positive consanguinity history with sporadic mutation and pathogenic variant. Precocious puberty is a common complication of NF-1 with a higher incidence compared with the general population and it happens mainly due to the optic pathway tumors. ${ }^{17}$ However, precocious puberty could be found in NF-1 patients with normal optic pathways but with the same frequency as in the normal population. ${ }^{17}$ Because precocious puberty is considered a frequent presentation in NF-1 patients, evaluating children growth and sexual development on a regular basis is one of the well-established health supervision guidelines for NF-1 children from the American Academy of Pediatrics. ${ }^{18}$

The last case that has been found in this study was a 73year-old woman who had a positive history of consanguinity with familial mutation of NF-1 and pathogenic variant. She presented with concurrent bilateral pheochromocytoma, multinodular goiter, and primary hyperparathyroidism (PHPT) due to parathyroid adenoma. Recent studies have reported that phaeochromocytomas/paragangliomas (PHAEO/PG) in NF-1 patients have a higher prevalence rate, especially when screening asymptomatic and normotensive NF-1 patients prospectively that suggested an underestimation of true prevalence. ${ }^{19,20}$ The Mayo clinic group recommended having biochemical testing for PHAEO/PG every 3 years starting at age 10 to 14 years as well as prior to any surgical procedure and conception to prevent an undesirable adverse event. ${ }^{2}$ Although the association between PHPT and NF-1 is rare and remains unknown, it has been reported. ${ }^{21}$ Since the 1970 s, there have been $\sim 20$ cases of PHPT in NF-1 reported in the literature. ${ }^{2}$ In Zöller's study, there was only one case of parathyroid adenoma in a 71-yearold woman. ${ }^{22}$ Interestingly, the coexistence of pheochromocytoma and PHPT has been reported in a few cases as in Altinova, and AL-Wahhabi studies of a 37-year-old man and a 65-year-old man with bilateral pheochromocytoma and PHPT due to parathyroid adenoma, respectively. ${ }^{23,24}$ It has been implied that the association between PHPT and PHAEO/PG could be a variant of MEN2. ${ }^{24,25}$ However more studies are required to determine the actual link between NF-1 and MEN2.

\section{Conclusion}

In conclusion, this study showed that short stature and precocious puberty are important manifestations in NF-1 patients that are affecting $8.06 \%$ and $1.61 \%$, respectively.
Hence, supporting the adherence to guidelines that have already been implemented by the American Academy of Pediatrics. Although subclinical hypothyroidism associated with NF-1 was rarely mentioned in the literature, it was noted in $6.45 \%$ of NF1 cases in this study, which promotes the screening of thyroid function tests to manage patients early and accordingly. Further studies are warranted to address the need for screening thyroid nodules in NF-1 by ultrasonography as they have an increased risk of cancer. The coexistence of PHPT and PHAEO/PG would expand the range of endocrine abnormalities in NF-1 patients. However, given the concurrence between endocrine abnormality and NF-1 in this study, detailed clinical analysis together with endocrine laboratory and imaging screening for patients with NF-1 should be considered to provide early diagnosis and management and avoid complications.

\section{Limitations}

The limitations of this study were the retrospective chart review method as the main source for data collection and the relatively small sample size. Therefore, further prospective studies with a larger sample size and involvement of other national tertiary hospitals are recommended.

\section{IRB Approval Status}

This study was reviewed and approved by the institutional ethics committee at King Abdullah International Medical Research Center (RC19/306/R).

Funding

None.

Conflict of Interest

None declared.

\section{References}

1 van Lierop ZYGJ, Jentjens S, Anten MHME, et al. Thyroid Gland ${ }^{18} \mathrm{~F}$ FDG Uptake in Neurofibromatosis Type 1. Eur Thyroid J 2018;7 (03):155-161. Doi: 10.1159/000488706

2 Wong CL, Fok CK, Tam VH. Concurrent primary hyperparathyroidism and pheochromocytoma in a Chinese lady with neurofibromatosis type 1. Endocrinol Diabetes Metab Case Rep 2018; 2018:18-0006. Doi: 10.1530/EDM-18-0006

3 Pop R, Neagoe R, Kolcsar M, Paşcanu I. Endocrine dysfunction in neurofibromatosis type 1-an update. Acta Med Marisiensis 2016; 62(01):155-158. Doi: 10.1515/amma-2016-0003

4 Ledbetter DH, Rich DC, O'Connell P, Leppert M, Carey JC. Precise localization of NF1 to $17 \mathrm{q} 11.2$ by balanced translocation. Am J Hum Genet 1989;44(01):20-24

5 Poyhonen M, Kytölä S, Leisti J. Epidemiology of neurofibromatosis type 1 (NF1) in northern Finland. J Med Genet 2000;37(08): 632-636. Doi: 10.1136/jmg.37.8.632

6 Cimino PJ, Gutmann DH. Neurofibromatosis type 1. Handb Clin Neurol 2018;148:799-811. Doi: 10.1016/B978-0-444-64076-5.00051-X

7 Bizzarri C, Bottaro G. Endocrine implications of neurofibromatosis 1 in childhood. Horm Res Paediatr 2015;83(04):232-241. Doi: 10.1159/000369802

8 Al-Sharefi A, Perros P, James RA. Phaeochromocytoma/paraganglioma and adverse clinical outcomes in patients with neurofibromatosis-1. Endocr Connect 2018;7(10):R254-R259. Doi: 10.1530/EC-18-0208 
9 Yao R, Yu T, Xu Y, et al. Clinical presentation and novel pathogenic variants among 68 Chinese neurofibromatosis 1 children. Genes (Basel) 2019;10(11):847. Doi: 10.3390/genes10110847

10 Güler S, Yeşil G, Önal H. Endocrinological evaluations of a neurofibromatosis type 1 cohort: is it necessary to evaluate autoimmune thyroiditis in neurofibromatosis type 1? Balkan Med J 2017;34(06):522-526. Doi: 10.4274/balkanmedj.2015. 1717

11 Diazzi C, Guidi A, Luberto A, Taliani E, Madeo B, Rochira V, Carani $C$. Thyroid disease in patients with type-1 neurofibromatosis: an underestimated issue? Endocr Abstr 2011:452

12 Nabi J. Neurofibromatosis type 1 associated with Hashimoto's thyroiditis: coincidence or possible link. Case Rep Neurol Med 2013;2013:910656. Doi: 10.1155/2013/910656

13 Doulias T, Papaziogas B, Rosser JH, Koutelidakis I. Thyroid neurofibroma in a female patient with neurofibromatosis type I: report of a case. BMJ Case Rep 2013;2013:bcr2012008216

14 Monzani A, Prodam F, Rapa A, et al. Endocrine disorders in childhood and adolescence. Natural history of subclinical hypothyroidism in children and adolescents and potential effects of replacement therapy: a review. Eur J Endocrinol 2012;168(01):R1-R11

15 Hussain F, Iqbal S, Mehmood A, Bazarbashi S, ElHassan T, Chaudhri N. Incidence of thyroid cancer in the Kingdom of Saudi Arabia, 2000-2010. Hematol Oncol Stem Cell Ther 2013;6(02):58-64. Doi: 10.1016/j.hemonc.2013.05.004

16 Kim BK, Choi YS, Gwoo S, Park YH, Yang SI, Kim JH. Neurofibromatosis type 1 associated with papillary thyroid carcinoma incidentally detected by thyroid ultrasonography: a case report. J Med Case Reports 2012;6(01):179. Doi: 10.1186/1752-1947-6-179

17 Virdis R, Sigorini M, Laiolo A, et al. Neurofibromatosis type 1 and precocious puberty. J Pediatr Endocrinol Metab 2000;13 (Suppl 1):841-844. Doi: 10.1515/jpem.2000.13.s1.841
18 Lodish MB, Stratakis CA. Endocrine tumours in neurofibromatosis type 1 , tuberous sclerosis and related syndromes. Best Pract Res Clin Endocrinol Metab 2010;24(03):439-449. Doi: 10.1016/j. beem.2010.02.002

19 Gruber LM, Erickson D, Babovic-Vuksanovic D, Thompson GB, Young WF Jr, Bancos I. Pheochromocytoma and paraganglioma in patients with neurofibromatosis type 1. Clin Endocrinol (Oxf) 2017;86(01):141-149. Doi: 10.1111/cen.13163

20 Képénékian L, Mognetti T, Lifante JC, et al. Interest of systematic screening of pheochromocytoma in patients with neurofibromatosis type 1. Eur J Endocrinol 2016;175(04):335-344. Doi: 10.1530/EJE-16-0233

21 Behera KK, Nanaiah A, Gupta A, Rajaratnam S. Neurofibromatosis type 1 , pheochromocytoma with primary hyperparathyroidism: a rare association. Indian J Endocrinol Metab 2013;17(02): 349-351. Doi: 10.4103/2230-8210.109670

22 Zöller M, Rembeck B, Odén A, Samuelsson M, Angervall L. Malignant and benign tumours in patients with neurofibromatosis type 1 in a defined Swedish population. American Cancer Society 1997;79:2125-2131https://doi.org/10.1002/(SICI)10970142(19970601)79:11\%3C2125::AID-CNCR9\%3E3.0.CO;2-N)

23 Altinova AE, Toruner F, Cimen AR, et al. The association of neurofibromatosis, bilateral pheochromocytoma and primary hyperparathyroidism. Exp Clin Endocrinol Diabetes 2007;115 (07):468-470. Doi: 10.1055/s-2007-981661

24 Al-Wahhabi B. Parathyroid adenoma and bilateral pheochromocytoma in a patient with neurofibromatosis. Ann Saudi Med 2005;25(03):255-257. Doi: 10.5144/0256-4947.2005.255

25 Favere AM, Tsukumo DM, Matos PS, Santos SL, Lalli CA. Association between atypical parathyroid adenoma and neurofibromatosis. Arch Endocrinol Metab 2015;59(05):460-466. Doi: 10.1530/EDM-18-0006 